\title{
PROYECTO SOCHEO: ACIERTOS Y FRACASOS DE UN CONTRA-ARCHIVO (INTER)MEDIA
}

\author{
Project Socheo: hits and failures of a counterfile (inter) media \\ Projeto Socheo: acessos e falhas de um contra arquivo de (inter) mídia \\ Fernando Redondo Neira \\ Universidad de Santiago de Compostela \\ fernando.redondo@usc.es \\ Xurxo González Rodríguez. \\ Director de Proyecto Socheo \\ xgonrod@josenaltavista.org
}

\section{Resumo}

Projeto Socheo é uma tentativa de contrariar o impacto do esquecimento que a passagem do tempo produz na Guarda, uma vila de pescadores na costa da Galiza (Espanha). Este arquivo digital (e disponível na web) visa reunir no mesmo local todas aquelas imagens que representam um reforço para evitar a fragilidade da memória coletiva.

Vivemos uma época em que muito material audiovisual é jogado fora todos os dias. Pretendemos aqui recuperá-la e preservá-la para, desta forma, contribuir para o enriquecimento do património de um povo com uma longa tradição marítima e um património histórico de enorme valor. Procuramos, desta forma, promover uma forma de repensar o passado, torná-lo presente e redimensioná-lo para o futuro.

Palavras-chave: Arquivo. Memória. Imagem

\begin{abstract}
Proxecto Socheo is an attempt to counteract the impact of oblivion which is produced by the pass of time in A Guarda, a fishing village on the coast of Galicia (Spain). This digital file (available on the web) aims to gather in the same location all those images that represent a reinforcement to avoid the fragility of the collective memory.

We live in times in which a lot of audiovisual material is thrown away every day. Here we try to recover and preserve it to, in this way, help enrich the heritage of a people with a long seafaring tradition and a historical heritage of enormous value. We try, in this way, to promote a way of rethinking the past, making it present and resizing it for the future.
\end{abstract}

Key words: Archive. Memory. Image.

\section{Resumen}

Proxecto Socheo es un intento de contrarrestar el impacto del olvido que produce el paso del tiempo en A Guarda, un pueblo marinero en la costa de Galicia (España). Este archivo digital (y disponible en la red) pretende reunir en un mismo emplazamiento todas aquellas imágenes que supongan un refuerzo para evitar la fragilidad de la memoria colectiva. 
Vivimos en tiempos donde a diario se deshecha un montón de material audiovisual. Aquí pretendemos recuperarlo y preservarlo para, de esta manera, ayudar a enriquecer el patrimonio de un pueblo de larga tradición marinera y un patrimonio histórico de un enorme valor. Intentamos, de este modo, promover una manera de repensar el pasado, hacerlo presente y redimensionarlo para el futuro.

Palabras clave: Archivo. Memoria. Imagen.

\section{INTRODUCCIÓN}

"Socheo" es una palabra gallega que en su acepción principal indica un momento indeterminado antes de que llegue la pleamar, en la fase creciente de la marea (PENA, 2003, P. 293). Una denominación de un espacio y tiempo sin concretar que fácilmente puede ser la distancia intermareal en cualquiera de su amplitud, sean mareas vivas o muertas. No obstante, dentro de los localismos de la semántica también es como se nombra la distancia entre la parte alta y la baja de una ola de mar. Por lo tanto, cuando la gente del mar de A Guarda habla de que "hay mucho socheo" quiere decir que "anda mucho el mar". Lejos de mostrar las incongruencias o disparidades de la geografía marítima, esta palabra es una excelente metáfora de lo que sucede hoy en día con la ontología del mundo de los archivos, es decir, la posición dialéctica entre dos puntos álgidos y antónimos, de su carácter serial y repetitivo, de las amplitudes y encadenamientos diferentes y, sobre todo, de la impresión de carencia de totalidad. Y, así, nos gustaría que cuando se escuche de nuevo lo de "hay socheo", que la gente lo relacione también porqué continúa existiendo el archivo que posee esta denominación: Proyecto Socheo1. Y para que esto suceda deben seguir apareciendo olas y olas de documentos audiovisuales.

Actualmente vivimos un tiempo en el que predomina la hipertrofia del recuerdo y el almacenamiento. La desconfianza hacia la estética y la naturaleza del objeto que alumbró espíritus transgresores, tanto en el campo social como artístico, dio paso a la emergencia de otro paradigma consistente en la valoración del archivo como consecuencia del conformismo social, especialmente el burocrático, y de la organización del trabajo (GUASH, 2011, P. 9). Ahora, además de crear imágenes, se necesita registrar, coleccionar y almacenar. A todo tenemos que asignarle un lugar, el "principio de agrupamiento", una filiación de acceso en el que satisfacer la curiosidad extrema, "el mal del archivo" (que diría Derrida en su famoso diagnóstico freudiano) que domina a nuestros tiempos (DERRIDA, 1997, p. 9).

\footnotetext{
${ }^{1}$ https://proxectosocheo.wordpress.com/ 
De la singularidad de un proyecto como el de Socheo se han ocupado ya estudiosos del audiovisual en Galicia. Cibrán Tenreiro, por ejemplo, ha destacado que Socheo hace circular estos documentos, antes ocultos o abandonados; crea un espacio que acoge también documentos nuevos y permite que la comunidad pueda dar testimonio de sí misma en presente, para lo cual no necesita del concurso de otros cineastas para dar cuenta de sus propias experiencias (TENREIRO, 2020. p. 56).

A partir de estas premisas, nuestro objetivo será el análisis de la utilidad y funcionamiento de un archivo audiovisual que opera a nivel local, centrándonos fundamentalmente en sus fortalezas y debilidades, tal y como estas se han ido manifestando a partir de la propia evolución del archivo.

\section{TEORÍA DEL ARCHIVO}

Proyecto Socheo es una puesta en valor de los archivos audiovisuales del pueblo de A Guarda (Pontevedra, España). Lejos de seguir el "principio de procedencia”, que acuñó Aby Warburg, se limitó el campo de actuación para tener mayor incidencia ya que el conocimiento del territorio favorece el éxito de la producción. La puesta en práctica de este proyecto en esta localidad pontevedresa se debe, también, a que allí se ejemplifica a la perfección el significado de archivo, una palabra que viene del griego, con claras alusiones al poder, y que significa "mandato de hechos en un lugar y en una época determinada" (DERRIDA, 1997, P. 9). ${ }^{2}$ En los últimos años, aprovechando la desidia social, se produjeron extrañas y anómalas “apropiaciones" de archivos fotográficos locales (Táboas, Hueto, Costiña, Sobrino, Valencia, Rivas, Cadilla, Costas, París). Esta situación hay que contemplarla como algo que raya la ilegalidad contra el patrimonio en vez de suscribirla como una consecuencia de la deriva posmoderna. Este material fotográfico pasó a la categoría de "tesoro", del cual se instrumentaliza de manera consciente su acceso. La referencia a Foucault parece inevitable en este caso: “(...) en toda sociedad la producción de discursos está a la vez controlada, seleccionada y distribuida por cierto número de procedimientos que tienen como función

\footnotetext{
2 "Arkhe, recordemos, nombra a la vez el comienzo y el mandato. Este nombre coordina aparentemente dos principios en uno: el principio según la naturaleza o la historia, allí donde las cosas comienzan -principio físico, histórico, ontológico,-, mas también el principio según la ley, allí donde los hombres y los dioses mandan, allí donde se ejerce la autoridad, el orden social, en ese lugar desde el cual el orden es dado (...)". (cursivas de los autores) (DERRIDA, 1997, p. 9).
} 
conjugar sus poderes y peligros, dominar el acontecimiento aleatorio y esquivar su pesada y terrible materialidad" (2002, p. 14).

Dando el material fotográfico histórico de A Guarda por inasible, el Proyecto Socheo se centra en clasificar los excedentes audiovisuales que tienen cierto interés como documento social y cultural para el pueblo. Es decir, un proceso científico y metodológico con el cual detectar los engranajes culturales, las huellas y símbolos visuales que acaban grabados por la Historia. Partimos de la base de la discontinuidad benjaminiana que echaba a bajo el concepto hegeliano de la dinámica lineal de la Historia. El material de los archivos viene a ejemplificar las características "socheadoras" de los archivos basados en la de-construcción del pasado, en la dialéctica, en la fragmentación, en la potencialidad rizomática, en la falta de jerarquía, en la estratificación, en la constatación de la diferencia y en su naturaleza inconclusa. Porque muchas veces no es la presencia, sino la ausencia lo que es significativa ya que aporta información sobre lo perdido, lo desplazado, lo relegado y lo oculto. O como también afirma Marc Ferro: "El film no vale solo por aquello que atestigua, sino por la aproximación social que autoriza" (1980. p.27).

Es en este punto donde todo es posible con una excelente "arquitectura de archivo", un espacio y un tiempo donde alojar el archivo y eso propició la llegada de la tecnología digital, concretamente los canales de Youtube. Los archivos digitales están generando una "nueva cultura de la memoria". Los archivos en la red tienen una condición espectral ya que están en lo que puede considerarse un no-lugar, desechando la idea clásica de la imagen, documento y monumento del propio archivo. Una consideración conceptual del archivo que se incrementa al estar indexado dentro del mega-archivo que es internet. No obstante, lejos de ser un lastre, redobla las posibilidades al permitir el re-archivo, incorporando meta-archivos procedentes de otras fuentes y sobre todo a la hora de difundir el archivo haciéndolo presente en las redes sociales.

Esta capacidad inter-media es también bidireccional. El nivel tecnológico alcanzado permite elevar los grados de accesibilidad a los archivos, así como una mayor consideración social al ponerlo al servicio de una comunidad que se erige como nuevo sujeto de la Historia (JAMESON, 1991, p. 69). La democratización de la tecnología hace posible lo impensable hasta hace bien poco: que el individuo se sienta parte del archivo y colabore de manera decisiva con el mismo. Por un lado, tenemos la legitimidad de las contribuciones al valorar el carácter polifacético de las imágenes ya que, al margen de lo muy privado, es muy difícil que una imagen no posea valor documental. De esta manera, toda esta apertura hace que Proyecto Socheo 
alcance la valoración de "contra-archivos" que atacan directamente a la concepción de archivo institucionalizado

Al hilo de lo anterior, Proyecto Socheo constituye una propuesta de antropología visual de nuestra sociedad a través del microcosmos guardés. Un protocolo efectivo para evitar la evaporación de la memoria colectiva, Una manera de salvaguardar el pasado, reactualizarlo en el presente y proyectarlo hacia el futuro. Aquella memoria colectiva adquiere, así, su sentido pleno, cuando el pasado ya no se considera, en absoluto, como materia inerte e inalterable. Antes al contrario, "se considera el pasado en su doble vertiente de origen y destino, pues este es permanentemente evocado, fortalecido y transmitido" (LARRIÓN, 2008, p. 73). Unas fases que hacen inútil la consideración en tiempo real ya que los frutos de un archivo siempre son tardíos. Una fuerza anarco-archivística retardada donde volver a reconocer las escrituras de un sistema de relaciones sociales. Un álbum inconsciente de una identidad revelada a la hora de practicar una arqueología siguiendo los estratos de tiempos, épocas, formas y gustos.

Un archivo de estas características nos sitúa, además, ante lo que Maurice Halbwachs denomina, evocando el título de su libro, "lo marcos sociales de la memoria". Los documentos audiovisuales recuperados por Socheo constituirían, aplicando los postulados de este pensador, aquella representación colectiva que comprende todo cuando es necesario para explicar la producción o la reproducción de los estados de consciencia individuales y, en particular, de los recuerdos (HALBWACHS, 2004, p.326). Lo que aquí está en juego es, en definitiva, la relación entre lo individual y lo colectivo, considerado esto último como "puntos de referencia" que llevamos con nosotros y que podemos localizar al observar nuestro entorno, pensar en los otros y reubicarnos en el marco social (HALBWACHS, 2004, p.327).

Proyecto Socheo es una invitación a evocar, sin la mediación del periodista o del cineasta profesional, la "memoria narrativa", un modo de contar la historia hilvanando narrativas secundarias y discontinuas, es decir, conscientes de que siempre se está en una posición incompleta. Sin embargo, esta consideración de Socheo es la evidencia de que el propio archivo hay que valorarlo como si fuera pensamiento, no quedarse solo en las imágenes, sino ir más allá de lo que estas muestran. Dicho en palabras de Deleuze: "Pensar es, en principio, ver y hablar, pero a condición de que el ojo no se quede en las cosas y se eleve la visibilidad, a condición de que el lenguaje no se quede en palabras o frases y alcance el enunciado. El pensamiento es como un archivo" (1999, p. 156). Para ello, lo audiovisual, tal como destaca Carmen Guarini, incide sobre la memoria por partida doble: como entorno mediático a modo de fuente ilimitada de elementos a rememorar y como soporte significativo para la conservación 
social de todo aquello que da cuenta del desarrollo de la historia (GUARINI, 2002, P. 115).

\section{LÍNEAS DE ACTUACIÓN}

Socheo es un proyecto a largo plazo. Solo así se pueden comprender los resultados. Deben ir en paralelo a la marcha del tiempo para que sedimenten documentos y acciones, para que los sustratos sean significativos. De esta manera, vemos la necesidad de flexibilidad, de ir cambiando estrategias y trenzar de una manera más intensa una noción de la memoria marcada por la necesidad del presente. No obstante, a pesar de llevar más de un lustro trabajando, ya podemos fijar cuales son los frentes abiertos. Las líneas de actuación diseñadas son variadas. Podemos agruparlas en los siguientes puntos:

1. Concienciación y valoración del audiovisual como herramienta social.

Este es el objetivo clave para desarrollar el resto del proyecto. Llegar a la comunidad, hacer ver la importancia de cuidar el material guardado en los archivos caseros. Persuadir acerca de su potencialidad como testigo de la historia y, al mismo tiempo, que la ciudadanía valore su aporte, el de los demás y el conjunto del archivo. En definitiva, que los miembros de la comunidad se sientan orgullosos de su singularidad interpelando a los contenidos de las imágenes.

2. Recogida de material audiovisual.

Este proyecto se inició con un proceso de localizar, estudiar, digitalizar, clasificar y divulgar todos los aportes de los vecinos del pueblo. Este es un proceso enmarcado dentro de una metodología férrea de clasificación y archivo con el objetivo de facilitar el acceso y visualización por parte de cualquier interesado.

3. Producción de documentos.

Realizar grabaciones ex-novo sobre elementos culturales de A Guarda de los que se requiere divulgar sus particularidades o porque peligre su conservación. En este último aspecto conviene centrarse, sobre todo, en el caso de informantes de elevada edad.

\section{RELACIONES AFECTIVAS CON LA COMUNIDAD}

El nacimiento de Proyecto Socheo vino casi demandado por la comunidad. Con el motivo de la proyección en A Guarda de Vikingland, una película de recuperación de archivo realizado por Xurxo Chirro en 2011, algunos espectadores indicaron que tenían grabaciones semejantes y proponían crear con ellas una nueva película. Esto se desestimó, pero a cambio de crear una plataforma para poner en valor ese material. 
En un principio se valoró la posibilidad de incorporar fotografías, pero el material estaba muy disperso y el campo de actuación se complicaba debido a los intereses creados y a las malas prácticas. Tras este diagnóstico se procedió a diseñar un archivo que solo estuviera integrado por piezas audiovisuales. No había muchas esperanzas de que Proyecto Socheo tuviera mucha vida. Sin embargo, los vecinos fueron respondiendo y fueron contribuyendo con material de todo tipo. El "boca-oreja" se tornó en el más eficaz de las herramientas de comunicación. La gente preguntaba en qué consistía el proyecto y como podía colaborar. Muchos vecinos aportaban cintas de VHS y DVD que dejaban en los buzones de correo de los distintos domicilios de las personas que constituyen el equipo de trabajo.

Cuando los interesados en compartir aportan un formato analógico se le devuelve el material original acompañado con una copia digital en un DVD. Nunca se conserva el original. Proyecto Socheo carece de capacidad para desempeñar esas funciones, por lo que aconseja siempre dirigirse al Centro Galego de Artes da Imaxe, la Filmoteca de Galicia, si no considera que esta opción mejore las condiciones de conservación en el domicilio. El proceso de digitalización es complejo. Hay formatos magnéticos que se pueden transformar pero otros, como el celuloide, necesitan de ayuda externa. Es aquí donde Proyecto Socheo genera gasto económico. El tiempo y el trabajo depositado en este proceso se compensan con las reacciones de la gente y con la idea de interacción social que promueve experiencias de este tipo.

En esta campaña de recogida, además, se diseñaron distintas actividades para dar a conocer los objetivos del archivo: diseño de carteles y panfletos para pedir la colaboración ciudadana, recogidas de material en distintos locales hosteleros y presentaciones en el auditorio local, en sedes de asociaciones y en colegios. Al poco tiempo, Proyecto Socheo trascendió de su territorio natural siendo invitado a contar la "experiencia socheo" más allá del ámbito local. Se hicieron presentaciones en filmotecas, festivales, muestras, congresos, laboratorios... tanto a nivel gallego, estatal como en el extranjero. Esta apreciación exterior se canalizó en intentar despertar interés en la proximidad, en que la gente se preguntara si las películas que tienen en el armario pueden tener valor más allá del disfrute personal. Gracias al responsable de comunicación, Proyecto Socheo tuvo eco en distintos medios: prensa escrita, radio y televisión. Para la divulgación de los documentos del archivo el mejor medio son las redes sociales y para tal cometido se diseñó una web que permitiera multiplicar el alcance de los vídeos. Una transparencia del trabajo archivístico que atrajo a otros propietarios a ceder sus documentos.

Fue así como se pudo llegar a fondos de los que ni siquiera se conocía su existencia. Destacan sobre todo la aportación de video-bitácoras, un subgénero peculiar en el que los 
marineros utilizan primero el cine y después el vídeo para visibilizar ante la comunidad su trabajo. Las grabaciones reciben la denominación de los distintos barcos: Canero, Tania-María, Pinillos Primero, Playa de Somo, Nuevo Cedes y Amel. Cabe destacar aquí la aparición de un gran número de fondos personales de quienes tenían como afición el cine de Súper 8 desde finales de la década de los sesenta hasta inicios de la década de los ochenta. Se identificaron estos fondos con los nombres y apellidos de los cineastas aficionados: José Quintas Núñez, Ramón Pérez (médico), Milo Valterra, José Antonio Uris, José Carlos Rebollar o Enrique Barreiro.

Finalmente, se dio un tercer paso: Socheo se puso en contacto con otros agentes sociales, asociaciones e instituciones que ya llevan años trabajando en A Guarda. Tras obtener cierto bagaje, tanto el trabajo hecho como la repercusión mediática hicieron notar que era el momento de establecer un diálogo con los responsables de asociaciones culturales (C. S. O Fuscalho, ACAMO, Piueiro), asociaciones deportivas (Club de Remo Robaleira, Club de Xadrez Albatros), instituciones gubernamentales (Concello da Guarda, Diputación de Pontevedra) o centros educativos (CEIP As Solanas, IES A Sangriña). La mayoría de las veces se establecieron sinergias positivas gracias al diálogo con estos agentes: revisamos los archivos, inventariamos, digitalizamos, divulgamos...

Especialmente destacable es el trabajo realizado con A Sangriña, uno de los institutos del pueblo donde se proporcionaron clases de educación audiovisual en lo que se llamó Socheo Educativo. Durante dos cursos completos, 2013-2014 y 2015-2016, se organizaron clases complementarias de acercamiento al mundo del cine y del audiovisual. Consistía, sobre todo, en profundizar en el mundo audiovisual y en la utilización coherente de sus herramientas más cercanas, como es el caso del teléfono móvil. También se enseñaba lenguaje audiovisual e historia del cine. Pero sobre todo, el elemento diferencial era la práctica constante, estableciéndose una serie de ejercicios desde la sencillez más rotunda hasta trabajar en la realización de un cortometraje a una escala más profesional.

Aparte de Socheo Educativo, también se proyectaron en los colegios de primaria las películas de Joaquín García Portela, más conocido como "Costiña". Este material tiene el valor de ayudar a identificar al que es, en la actualidad, el pionero del cine en el pueblo. Para esta actividad tan especial se hicieron presentaciones y se trabajaron unidades didácticas pensadas para distintos niveles educativos.

Proyecto Socheo no se limita a establecer contacto con agentes locales, sino que intenta buscar afinidades más allá del territorio municipal. Así, se conectó con proyectos gallegos 
similares como O Faiado da Memoria ${ }^{3}$, de Vilagarcía de Arousa, Fálame de San Sadurniño ${ }^{4}$ o la Agrupación Cinematográfica de Galicia $^{5}$ (Vigo). Con este último se llegó a un acuerdo de colaboración para la digitalización de Súper 8. Pero lo más determinante en la confluencia de intereses y objetivos fue la participación, como socio fundador, de la Red de Cine Doméstico de España ${ }^{6}$. Con estas iniciativas se intercambia, se dialoga, se participa en proyectos y se resuelven posibles conflictos derivados del mundo del archivo.

\section{FRACASOS SIGNIFICATIVOS}

Está claro que la satisfacción alcanzada por los puentes tendidos hacia la comunidad fue fundamental para dar continuidad a Proyecto Socheo. Pero no todo se puede cifrar en clave de éxito y también hay que reseñar las experiencias negativas. Estos llamados fracasos hay que verlos con detenimiento y sin sonrojo, ya que, lejos de menoscabar la iniciativa, va a permitir trazar una aprovechable hoja de ruta en la que identificar las pautas que rigen el mundo del archivo en la actualidad.

El primer fracaso significativo podemos situarlo en la consideración comercial del archivo. Concretamente, esto sucedió en el caso de digitalización del mayor fondo audiovisual da Guarda: el de la televisión local Canal 50. Tras inventariar el fondo, Proyecto Socheo buscó un acuerdo con los propietarios en el que, a cambio del ingente trabajo de digitalización (cerca de 3.000 horas), se le permitiese hacer público parte de ese material. Esta consideración contractual fue vista con desconfianza, ya que se pensaba que se intentaría actuar con ánimo de lucro respecto de la gestión del archivo. Esta circunstancia motivó una gran suspicacia en torno al proceso, por lo que finalmente se hubo que desistir. No se duda del valor de las imágenes del fondo de Canal 50, pero resulta contraproducente su tasación monetaria ya que los documentos de un archivo adquieren plusvalía cuando dialogan con documentos de distintas procedencias. La sombra de que el trabajo de Proyecto Socheo se realiza porque hay compensación económica es algo que de vez en cuando surge cuando se establece contacto con algún potencial colaborador que está alerta ante prácticas archivísticas sospechosas. Es aquí cuando hay que redoblar los esfuerzos para explicar los principios del proyecto y ganarse la confianza del propietario del documento.

\footnotetext{
${ }^{3}$ http://www.ofaiadodamemoria.org/es/

4 http://www.falamedesansadurnino.org/

5 http://www.falamedesansadurnino.org/

6 https://redcinedomestico.wordpress.com/
} 
Otra piedra en el camino fue la dificultad para alcanzar una buena sintonía con las administraciones públicas. El conflicto estaba servido: por un lado el archivo se basa en la comunidad, pero las instituciones mostraron bastante recelo. Proyecto Socheo tiene una vocación de contra-archivo definido por su carácter abierto, sin protocolos ni dirigismos, participativo, aglutinador, crítico, sin prescripciones ideológicas... es decir, una plataforma de archivo muy volátil y de sistematización compleja Tras presentar en sociedad la iniciativa, el ayuntamiento de A Guarda creó su propio archivo: Tesouros vivos do mar, un proyecto que consiguió ayudas europeas del fondo FEDER y que tuvo una actividad reducida a un año. Esta duplicidad no ayudó a nadie. Aparte de echar en falta una gestión correcta y racional de los recursos, se creó mucha confusión entremezclando objetivos y procesos. La situación fue incómoda. ¿Cómo podía ser que un pueblo de las dimensiones de A Guarda tuviese en funcionamiento dos archivos? Según fue pasando el tiempo se fueron acercando posturas y, finalmente, en 2016, el ayuntamiento participó por primera vez con Proyecto Socheo en el homenaje al pionero del cine guardés: Joaquín García Portela "Costiña".

Uno de los fracasos de Proyecto Socheo está relacionado con la censura de contenidos. Al dar acceso público a sus documentos, recibió presiones por mostrarlos. Probablemente la censura sea el condicionante más antiguo que se puede encontrar una manifestación humana. Pero, a pesar de este temor, se pensó que en sociedades desarrolladas no se malgastaría el tiempo en discernir la idoneidad de los contenidos de un documento. El caso más destacado fue el protagonizado por la Organización de Palangreros Guardeses (ORPAGU), que contactó con Proyecto Socheo para sugerir la retirada de una serie de vídeos porque atentaban contra sus intereses. Concretamente, estaban en negociaciones para firmar un nuevo acuerdo pesquero y solicitaron retirar todos aquellos documentos gráficos que reflejaran modos de pesca agresivos y no sostenibles. En un principio Proyecto Socheo alegó que esos documentos mostraban un modo de pesca de un determinado momento histórico y que era inconcebible que alguien pudiese hacer lecturas en presente de lo que allí sucedía. ORPAGU continuó defendiendo sus argumentos y apuntó que Proyecto Socheo pretendía perjudicar al mayor sector económico de A Guarda. Finalmente, se accedió a la retirada de los videos a cambio de que los miembros de la asociación pesquera contribuyesen con el archivo aportando más videobitácoras, lo cual no llegaron a cumplir. Finalmente, Proyecto Socheo volvió a activar los videos de la discordia cuando ya no importaba, ni molestaba, a nadie porque el acuerdo se había firmado sin contratiempos. 
Si se hace un mínimo de autocrítica surge otro fracaso: la poca perspectiva empresarial. Tal como se indica en otras partes de este artículo, Proyecto Socheo es un contra-archivo, por lo que acarrea cosas muy positivas pero también negativas, sobre todo para reforzar su andamiaje y buscar vías de expansión. Pero para cumplir este objetivo el salto había que hacerlo en términos propios o parecidos a los de una empresa. En 2014 Proyecto Socheo ganó el Premio de Alfabetización Audiovisual del Ministerio de Cultura por su labor en el campo de la educación. En esa misma convocatoria, otra iniciativa de pedagogía de la imagen, Cine en Curso $^{7}$, consiguió el mismo reconocimiento, pero este buscó, con acierto, el apoyo de diversas instituciones, así como de financiación europea. Otra vez la circunstancia del campo de actuación juega en contra de buscar soportes para el desarrollo del proyecto. No obstante lo anterior, también hay que considerar qué modelo de proyecto ofrece mayor diálogo con la comunidad. Pero el gran error de Proyecto Socheo es el carecer de la capacidad de convencer a las autoridades de sus virtudes para que respalden este modo de pensar la imagen como sedimentación de hechos, experiencia o memoria de una determinada sociedad y del grupo humano que la habita.

La atribución de contra-archivo conlleva por definición la incapacidad de ajustarse a los baremos archivísticos. Poner en tela de juicio los convencionalismos que acarrea la ciencia archivística hace patente la capacidad de ajustarse a sus máximas por muy innovadoras que estas sean. Proyecto Socheo mantuvo contacto con archivos de instituciones provinciales y autonómicas para depositar en ellos copias de los documentos que están disponibles en la red y cederá sus fondos a cualquier institución que asegure unas condiciones mejores que las actuales. Con el Archivo de la Diputación de Pontevedra se establecieron negociaciones, pero no se contempla la cesión de discos duros. Por otra parte, el Archivo de Galicia contactó con pequeños archivos, entre ellos Proyecto Socheo, para poder englobarlos dentro de su proyecto denominado Galiciana. Pero aquí surgieron los habituales problemas de un archivo: el original, la copia, los propietarios, la custodia, los permisos, la catalogación...

Otro frente de batalla fueron las limitaciones mediadoras de las redes sociales. A esta altura de su evolución, percibimos como se fueron frustrando las esperanzas de perseverar en la conectividad de los miembros de la comunidad. Asistimos a un periodo de estancamiento para el futuro a corto plazo. Proyecto Socheo hizo gala de beneficiarse del contexto tecnológico. Así se constituyó como un archivo (inter)media capaz de propagarse con facilidad por internet.

\footnotetext{
${ }^{7}$ https://www.cinemaencurs.org/es
} 
Esta apuesta se hizo, sobre todo, en las redes sociales, donde se esperaba una mayor propagación de los hipervínculos de los documentos. Proyecto Socheo tiene especial actividad en Facebook, de la cual ya se puede definir una serie de comportamientos. Hay un número reducido de usuarios que siguen el perfil. También son pocos los que comparten las entradas y son reincidentes los que aportan comentarios. Se confiaba en que Facebook sería el gran dispositivo divulgador, un gran escaparate. Se pensó que tendría un mayor dinamismo, pero su uso es inconstante. Depende mucho del valor (histórico) del documento y de la estacionalidad. Otra de las carencias de las redes sociales es la escasa receptividad respecto de aquellos anuncios o invitaciones a colaborar con el archivo. Comprobamos aquí las dificultades de las redes sociales para hacer llamadas al público. Para seguir consiguiendo material se basa sobre todo en la relación física, personal. Una circunstancia que se debe a que de esta manera el colaborador obtiene un mayor grado de confianza.

Casi siguiendo el punto anterior hay que reconocer que las redes sociales no son archivos. Su arquitectura de programación no favorece las búsquedas históricas. Los perfiles de Facebook pueden consultar la cronología, pero actualmente está poco desarrollada y su búsqueda no es ágil ni dinámica. Las redes sociales se convirtieron en escaparates de inmediatez para, simplemente, sintonizar el presente. Así, es normal que la actividad registrada se mueva por comportamientos ciclotímicos derivados del interés o desapego que tenga el usuario por la actualidad. Inconscientemente, agrega documentos al servidor de Facebook que tras una vigencia de periodo temporal reducido se verá sepultado por el devenir. Esta pérdida de potenciales documentos se produce cuando el usuario carga los videos directamente en el servidor de Facebook. En su día Proyecto Socheo apostó por el Canal de Youtube ${ }^{8}$ para organizar su fondo. Esta plataforma sí satisface criterios archivísticos porque se pueden localizar rápidamente documentos por medio del buscador, las etiquetas, las listas de reproducción o las sugerencias.

Este contexto influye de manera determinante en la producción de documentos, ya que existe un reforzamiento de la autoría efímera. Actualmente, las nuevas tecnologías permiten que las cámaras de los móviles documenten nuestro día a día, siendo así los testigos fieles de nuestro devenir. Nunca existieron tantas cámaras y nunca existieron tantas imágenes. Somos capaces de capturar la realidad de una manera más fácil, lo que deriva en su exceso. Con este volumen se hace necesaria cierta selección marcada por diferentes criterios y, por último, se

8 http://www.youtube.com/c/ProxectoSocheo 
utilizan las redes sociales como el medio más inmediato para mostrarlas. En estos tres puntos es donde interviene la autoría: en la puesta en escena, en el montaje y en la exhibición. Esta transposición del proceso cinematográfico hace que ya no solo cualquiera pueda considerarse cineasta, sino que cualquiera tiene en su mano todo el proceso institucionalizado de la imagen. Un proceso muy rápido que dispone de muy poco tiempo para pensar la imagen, una rémora que sí se hace muy evidente en la fase de creación (y ya no digamos en dilucidar a donde va a parar la producción resultante).

Quizás el fracaso que más duele a Proyecto Socheo es la innumerable producción actual perdida. La incapacidad de incorporar la producción de documentos más actual es una sangría dolorosa. Gracias a las posibilidades de acceso de las nuevas tecnologías, se produce un ingente volumen de material audiovisual que es difícil que se depositen en Proyecto Socheo. Pese a las facilidades proporcionadas por la tecnología, el creador del documento prefiere engrosar su "archivo personal" para saciar sus ansias de autoría en vez de colaborar con un proyecto compartidos con otros. Proyecto Socheo hace constantes llamadas al público para que envíe sus vídeos, especialmente con motivo de las fiestas grandes de A Guarda, cuando hay algún logro deportivo o cuando se produce algún fenómeno de la naturaleza. Especialmente destacable, por lastimoso, fue el increíble número de vídeos que llegaron las redes durante el invierno de 2014 cuando el mar produjo una enorme cantidad de espuma debido a un temporal. Una espectacular estampa blanca trascendió a los medios de comunicación de medio mundo. Por el contrario, ninguno de esos vídeos llegó a Proyecto Socheo. Por otro lado, y paradójicamente, esta escasez contrasta con el exceso de imágenes de nuestros días. Con razón Ángel Quintana se pregunta cómo se confeccionarán los archivos del futuro frente al exceso de imágenes de todo tipo y formato. Alude, a este respecto, a Jorge Luis Borges, quien consideraba que la gran pesadilla del historiador del siglo XXI sería el exceso de materiales a su disposición (QUINTANA, 2011, p. 188).

El anterior fracaso nos encamina hacia otro de una manera inexorable. El archivo tiene que hacer distinción entre noticia y documento. Este es un debate lo bastante complejo como para tratarlo aquí de una manera superficial, pero el género periodístico siempre es un elemento que proporciona información de una manera directa. En A Guarda existen portales web de información local (Infominho, Telemariñas) que generan una gran cantidad de videos informativos. Estos ya tienen su propio archivo y su propio espacio en la red, por lo que no se antoja necesaria su inclusión en Proyecto Socheo. Por otra parte, muchos de los temas de esos vídeos sí poseen valor archivístico. De esta manera, imágenes recogidas de esos motivos por 
otros testigos sí se encuentran en Proyecto Socheo. Pero quizás podemos sistematizar los aportes documentales como aquellas producciones en imágenes que atesoran en sus contenidos patrimonio inmaterial de A Guarda, aquellos que, con el paso del tiempo, se dota de un valor de identidad que se hace cada vez más remarcable.

Por último, señalaremos como fracaso la máxima de Proxecto Socheo: el intento de asimilar el tiempo, su permanencia y devenir. Un archivo no se puede hacer de la noche a la mañana. Los documentos llegan sin una frecuencia determinada. Esto hace que se transiten largos períodos sin operatividad. La máxima de un archivo es quedar latente durante el mayor tiempo posible. El tiempo es un amigo, pero también puede ser un problema ya que un contraarchivo necesita estar siempre presente en el desarrollo de la comunidad en la que está inscrito.

\section{CONCLUSIONES}

Tras lo expuesto cabe pensar que un incremento del progreso se traduce en un mayor egoísmo a la hora de participar en un archivo comunitario. Pero esta máxima conviene redefinirla y podemos afirmar que la técnica sí define la participación. Ya quedó referida la fórmula de que la profusión del video HD reduce el deseo de incorporarlo a un archivo. Por el contrario, aquellos documentos en imágenes analógicas $(9,5 \mathrm{~mm}$, Súper 8 , VHS) sí es más proclive a formar parte de Proyecto Socheo. La razón es fácil de deducir y no es otra que la del intercambio: Proyecto Socheo digitaliza las bobinas o las cintas y a cambio de este trabajo el propietario tiene que autorizar su difusión en las redes tras un montaje acordado por ambas partes.

Llegados al final de esta exposición de fortalezas y debilidades, podemos sostener que Proyecto Socheo es un archivo (inter) media que ha demostrado su utilidad en la creación de un memoria colectiva, que contribuye a la recuperación, conocimiento y difusión del patrimonio inmaterial en el ámbito local, que es susceptible, en última instancia, de ser tomado como ejemplo para su puesta en práctica en otros territorios. Se dan, especialmente, tres circunstancias que lo hacen atractivo en este sentido: su conexión con la comunidad, por todo lo que innova su espíritu de contra-archivo y, finalmente, porque se adapta al panorama tecnológico. Este último aspecto, no obstante, presenta una doble dimensión, ya que por un lado potencia las afinidades sociales y cuestiona el inmovilismo de los archivos y. por otro, comprobamos como afloran rémoras que limitan su campo de acción. Pero curiosamente estos "fracasos" hacen de esta iniciativa una excelente herramienta con la cual poder discernir cuales van a ser los rumbos que podamos trazar ante la cada vez más accesible producción de imágenes. 


\section{REFERÊNCIAS}

Deleuze, G. (1990). Pouroarlers. París: Editions de Minuit.

Derrida, J. (1997). Mal de archivo. Una impresión freudiana. Madrid: Editorial Trotta.

Ferro, M. (1980). Cine e historia. Barcelona: Editorial Gustavo Gili.

Foucault, M. (2002). El orden del discurso. Barcelona: Tusquets.

Guarini, C. (2002). Memoria social e imagen. Cuadernos de Antropología Social, no 15. pp. 113-123.

Guasch, A. M. (2011). Arte y archivo 1920-2010. Madrid: Akal.

Halbwachs, M. (2004). Los marcos sociales de la memoria. Barcelona: Anthropos.

Jameson, F. (1991). El posmodernismo o la lógica cultural del capitalismo avanzado. Paidós:

Barcelona.

Larrión Cartujo, J. (2008). El orden de la desmemoria. La condición social de la memoria fragmentada, las memorias combativas y la ignorancia de nuestro tiempo. Anthropos. $\mathrm{n}^{\circ} 218$. pp. 6884.

Pena, X. A. (Dir.) (2005). Diccionario Século21 da lingua galega. Vigo: Editorial Galaxia e Edición do Cumio.

Quintana, A. (2011). Después del cine. Imagen y realidad en la era digital. Barcelona: Acantilado. Tenreiro C. (2020). Entre illas. Reciclaxe e arquivo no cinema galego. En Margarita Ledo Andión (Coord.). De illas e sereas. Para unha historia do cinema en lingua galega. Vigo: Galaxia. pp. 45-68. 
Licenciado en Ciencias de la Información por la Universidad del País Vasco (UPV) y doctor por la Universidad de Santiago de Compostela (USC). Profesor de Comunicación Audiovisual en la Facultad de Ciencias de la Comunicación de la USC. Miembro de la Asoacición Española de Historiadores del

Cine (AEHC), de la Asociación Gallega de Investigadores de la Comunicación (AGACOM) y del Centro de Estudios Fílmicos (CEFILMUS). Autor de Carlos Velo. Itinerarios do documental nos anos trinta y de Os amorodos de Bergman. Ha publicado artículos de investigación en revistas académicas como Signa o Estudios sobre el Mensaje Periodístico.

Xurxo González Rodríguez

Licenciado en Historia da Arte por la Universidad de Santiago de Compostela (USC). Crítico de cine

(Tempos Novos, Cahiers du Cinéma-España, Madrigal, etc.), documentalista y catalogador en archivos audiovisuales de Televisión Española en Galicia, coordinador del libro Manoel de Oliveira.

Profesor en el Máster de Conservación do Patrimonio (USC), trabajó para el Instituto Cesing, comisionado del ICAA del Ministerio de Cultura de España (2010-2011), guionista y realizador (como

Xurxo Chirro): Argazo, Os señores do vento, 36/75, 13 pozas, Cellular Movie, Vikingland, Une histoire seule, Jeanette. Director de Proxecto Socheo.

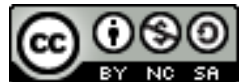

Esta obra está licenciada com uma Licença

Creative Commons Atribuição-NãoComercial-CompartilhaIgual 4.0 Internacional 